\title{
Analysis of Strength and Microstructural Characteristics of Mine Backfills Containing Fly Ash and Desulfurized Gypsum
}

\author{
Zhiqiang Huang ${ }^{1,2}$, Erol Yilmaz ${ }^{3}$ (D) and Shuai Cao ${ }^{1,2, *(\mathbb{D})}$ \\ 1 State Key Laboratory of High-Efficient Mining and Safety of Metal Mines of Ministry of Education, \\ University of Science and Technology Beijing, Beijing 100083, China; hzhiqiang1997@126.com \\ 2 School of Civil and Resources Engineering, University of Science and Technology Beijing, \\ Beijing 100083, China \\ 3 Geotechnical Division, Department of Civil Engineering, Recep Tayyip Erdogan University, Fener, \\ Rize TR53100, Turkey; erol.yilmaz@erdogan.edu.tr \\ * Correspondence: sandy_cao@ustb.edu.cn
}

\section{check for}

updates

Citation: Huang, Z.; Yilmaz, E.; Cao, S. Analysis of Strength and Microstructural Characteristics of Mine Backfills Containing Fly Ash and Desulfurized Gypsum. Minerals 2021, 11, 409. https://doi.org/ $10.3390 / \min 11040409$

Academic Editors: Abbas Taheri, Chongchong Qi, Guichen Li, Hakan Basarir, Qiusong Chen and Yuantian Sun

Received: 14 March 2021

Accepted: 8 April 2021

Published: 13 April 2021

Publisher's Note: MDPI stays neutral with regard to jurisdictional claims in published maps and institutional affiliations.

Copyright: (c) 2021 by the authors. Licensee MDPI, Basel, Switzerland. This article is an open access article distributed under the terms and conditions of the Creative Commons Attribution (CC BY) license (https:/ / creativecommons.org/licenses/by/ $4.0 /)$.

\begin{abstract}
The utilization of solid wastes (SWs) as a potential resource for backfilling is not only conducive to environmental protection but also reduces the surface storage of waste. Two types of SWs, including fly ash (FA) and desulfurized gypsum (DG), were used to prepare cementitious backfilling materials for underground mined-out areas. Ordinary Portland cement (OPC) was used as cement in mine backfill. To better investigate the feasibility of preparing backfill materials, some laboratory tests, such as uniaxial compressive strength (UCS), scanning electron microscopy (SEM), and energy dissipation theory, were conducted to explore both strength and microstructural properties of backfilling. Results have demonstrated that the main components of FA and DG in this study are oxides, with few toxic and heavy metal components. The ideal ratio of OPC:FA:DG is 1:6:2 and the corresponding UCS values are 2.5 and 4.2 MPa when the curing time are 7 days and 14 days, respectively. Moreover, the average UCS value of backfilling samples gradually decreased when the proportion of DG in the mixture increased. The main failure modes of various backfilling materials are tensile and shearing cracks. In addition, the corresponding relations among total input energy, dissipated energy and strain energy, and stress-strain curve were investigated. The spatial distribution of oxygen, aluminum, silicon, calcium, iron and magnesium elements, and hydration product are explored from the microstructure's perspective. The findings of this study provide both invaluable information and industrial applications for the efficient management of solid waste, based on sustainable development and circular economy.
\end{abstract}

Keywords: solid waste; sustainable waste management; strength characteristics; microstructural analysis; backfilling materials

\section{Introduction}

The extraction of ore resources has promoted the progress of human civilization, providing critical raw materials for sustainable development and circular economy [1,2]. However, it is irrefutable that resource mining has also caused a series of complications, such as water and air pollution [3], geotechnical risks [4], environmental hazards [5], farmland occupation [6], and tailings dam failures [7]. Solid waste output is growing at an annual rate of over 1 billion tons [8]. With the environmental protection policies and sustainable development goals, the whole use of solid waste has become a key strategy to building a resource-saving and environment-friendly city worldwide [9]. Solid wastes may cause some geotechnical and chemical instabilities if they are not well managed.

Wastes like fly ash (FA) and desulfurization gypsum (DG) are two main industrial solid wastes in Baotou city in Inner Mongolia, China [10]. Improving the utilization rate of FA and DG is one of the important technical problems to be solved by the industry [11]. At the moment, FA is mainly used as an additive for cement and the preparation of 
cementitious materials, while DG is mainly used to prepare gypsum-based new building materials [12,13]. Numerous scholars and engineers have conducted the feasibility of the above two types of solid waste utilization $[14,15]$. It was found that the risk assessment codes in FA posed no or low risk [16], while the heavy metals in DG showed a medium risk to the ecosystem [17]. In addition, the lime, FA, and DG were chosen as additives for investigating the solidification and stabilization of swelling soils [18]. Wang et al. [19] found that proper dosage and mineral additions affect the mechanical strength of the flue gas DG and FA system. Moreover, it was found experimentally that gypsum-based composites' properties improved due to the synergistic effect between industrial wastes and straw fibers [20].

The existence of underground mined-out areas seriously threatened workers and equipment; on the other hand, it severely restricts the reform of mining methods [21]. Especially for mines where there are toxic elements (e.g., cyanide, arsenic, and lead) in the ore itself, this effect is even more obvious [22]. Tailings are called solid waste or hazardous waste after ore processing $[23,24]$. They can also be prepared concrete additives, backfilling, and construction materials $[25,26]$. However, tailings containing toxic elements or heavy metal ions cannot be used for filling underground voids according to the related environmental protection standards [27-29]. Thus, exploring the feasibility of using FA and DG to prepare mine backfilling is the main purpose of this study. Scholars have so far used backfill samples with ecofriendly binders [30,31] and cement-based composites [32] on a single or combination of FA $[33,34]$ and DG $[35,36]$ as industrial waste.

In this study, cement, FA, and DG are utilized to prepare the backfill materials for underground voids. A series of laboratory tests, including uniaxial compressive strength, energy dissipation theory, and scanning electron microscopy, are conducted. The present study investigates the particle size distribution and chemical composition of FA and DG, strength and loading energy development, and cement-based backfills' microstructural characteristics. This study's main contribution is that it can provide a reliable reference for the feasibility of preparing mine backfills prepared with solid waste.

\section{Materials and Methods}

\subsection{Materials}

\subsubsection{Characteristics of FA and DG}

In this study, two solid wastes (e.g., FA and DG) obtained from Inner Mongolia were selected as additive materials for preparing the tested mine backfill specimens. Particle size distributions of these two materials were measured by the LSPOP (9) laser particle size analyzer (OMEC, Zhuhai, China). Figure 1 shows the particle size distributions of both FA and DG materials. Moreover, the physical properties of FA and DG materials were shown in Table 1.
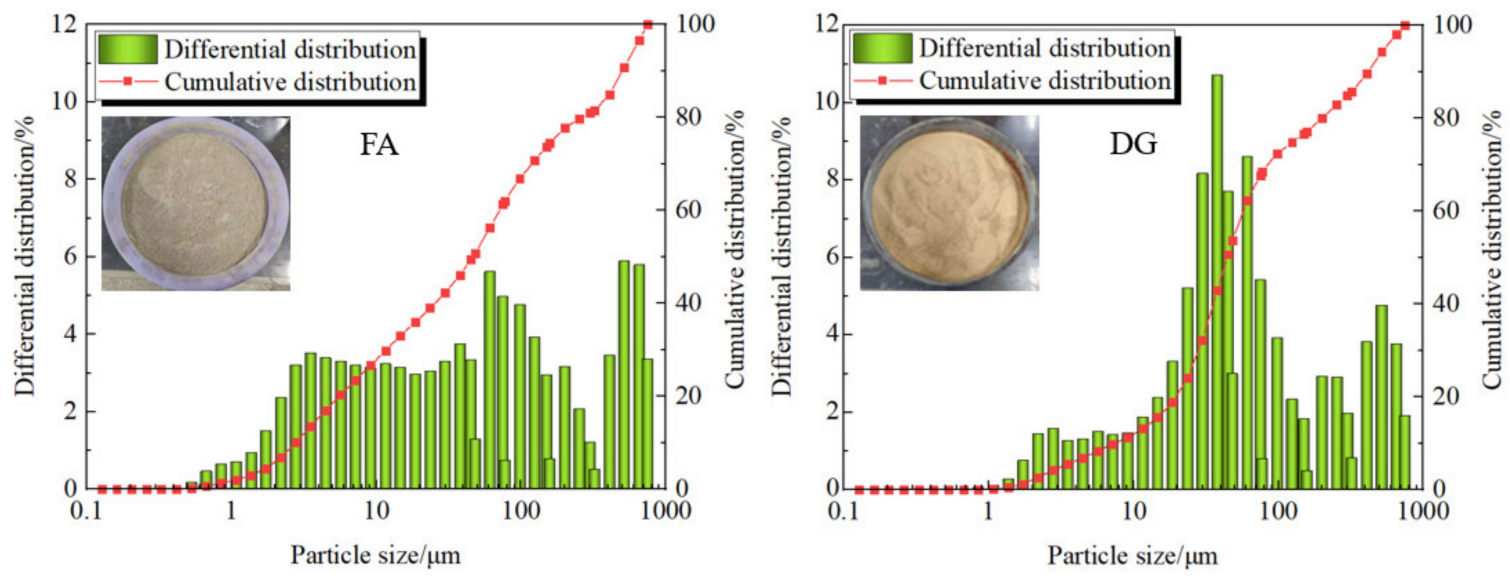

Figure 1. Particle size distributions of fly ash (FA) and desulfurization gypsum (DG) materials. 
Table 1. Physical parameters of FA and DG materials.

\begin{tabular}{ccccccc}
\hline Materials & D10 $(\mu \mathrm{m})$ & D25 $(\mu \mathrm{m})$ & D50 $(\mu \mathrm{m})$ & D75 $(\mu \mathrm{m})$ & D90 $(\boldsymbol{\mu m})$ & $\begin{array}{c}\text { Specific Surface Area } \\
\left(\mathbf{m}^{\mathbf{2}} / \mathbf{k g}\right)\end{array}$ \\
\hline FA & 2.766 & 8.067 & 46.324 & 163.687 & 499.833 & 737.135 \\
DG & 7.431 & 24.241 & 44.355 & 127.431 & 417.263 & 353.377 \\
\hline
\end{tabular}

The chemical composition of both FA and DG was tested by using the sequential X-ray fluorescence spectrometer from the University of Science and Technology Beijing, Beijing, China. The basic parameter including scanning velocity, voltage, and current were $300^{\circ} / \mathrm{min}, 60 \mathrm{kV}$, and $140 \mathrm{~mA}$, respectively. The X-ray fluorescence spectrometry was conducted to investigate the chemical composition of tested mine specimens in this study. The cement composition of FA and DG materials were listed in Figure 2.

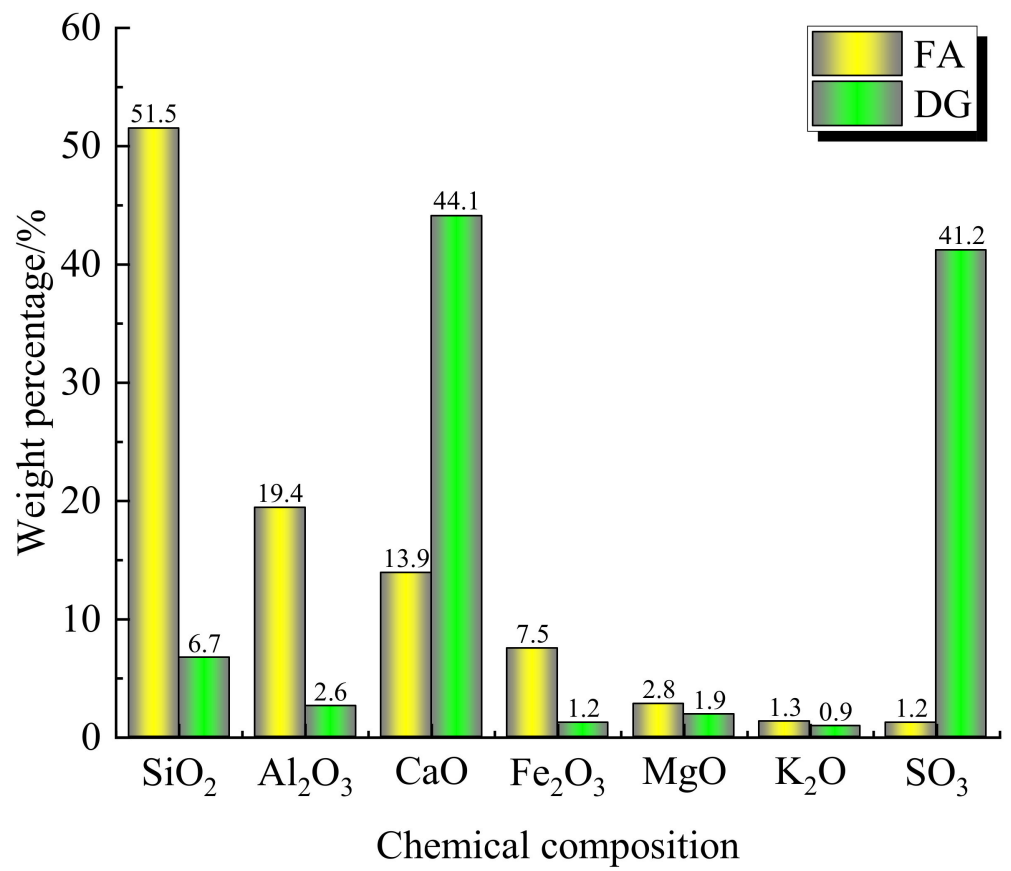

Figure 2. Chemical composition of FA and DG materials.

\subsubsection{Binder and Water}

In this study, the ordinary Portland cement from Chengxin Cement Manufacturing Co., Ltd from Tanshan in China named OPC 42.5R was selected as a basic binder for preparing the mine fill samples. The chemical composition of the cement used was shown in Table 2. Tap water was used to mix the FA, DG, and cement.

Table 2. Chemical composition of ordinary Portland cement (OPC) 42.5R.

\begin{tabular}{cccccccc}
\hline Chemical Composition & $\mathrm{SiO}_{2}$ & $\mathrm{Fe}_{\mathbf{2}} \mathbf{O}_{\mathbf{3}}$ & $\mathrm{Al}_{\mathbf{2}} \mathbf{O}_{\mathbf{3}}$ & $\mathbf{M g O}$ & $\mathrm{CaO}$ & $\mathbf{S O}_{\mathbf{3}}$ & $\mathbf{K}_{\mathbf{2}} \mathbf{O}$ \\
\hline content $(\%)$ & 20.1 & 2.91 & 5.11 & 1.57 & 61.8 & 1.98 & 0.37 \\
\hline
\end{tabular}

\subsection{Specimens Preparation and Curing Conditions}

Firstly, an electronic scale named AUW120D 220D with an accuracy of $0.01 \mathrm{~g}$ from Japan was used to weigh the FA, cement, DG, and water. Secondly, dry cement, FA, and DG were mixed at least for $3 \mathrm{~min}$. Tap water was poured into the stirring tank, and then the JJ-5 cement mortar mixer produced by Wuxi Jianyi Instrument Machinery Co., Ltd. was used to mix for 3 min again until the slurry was fully dispersed. The diameter and height of cylindrical molds were 50 and $100 \mathrm{~mm}$, respectively. Note that a recent experimental work 
by Yilmaz et al. [37] has been checking specimen size effect on compressive strength of cemented tailings or paste backfills, showing that samples with a diameter of 5 and $10 \mathrm{~cm}$ in height always gave better strength performance than other sample sizes $(\mathrm{D} \times \mathrm{H}: 7.5 \mathrm{~cm}$ $\times 15 \mathrm{~cm}$ and $10 \mathrm{~cm} \times 20 \mathrm{~cm}$ ) for a given cemented tailings backfill recipe. The slurry was poured into the molds and then placed in a curing box named HSBY-40B. The temperature and humidity were set as $20 \pm 1{ }^{\circ} \mathrm{C}$ and $90 \pm 5 \%$. The curing time were set as 7 and 14 days in this study. Figure 3 shows the entire process of the mine filling specimen preparation.
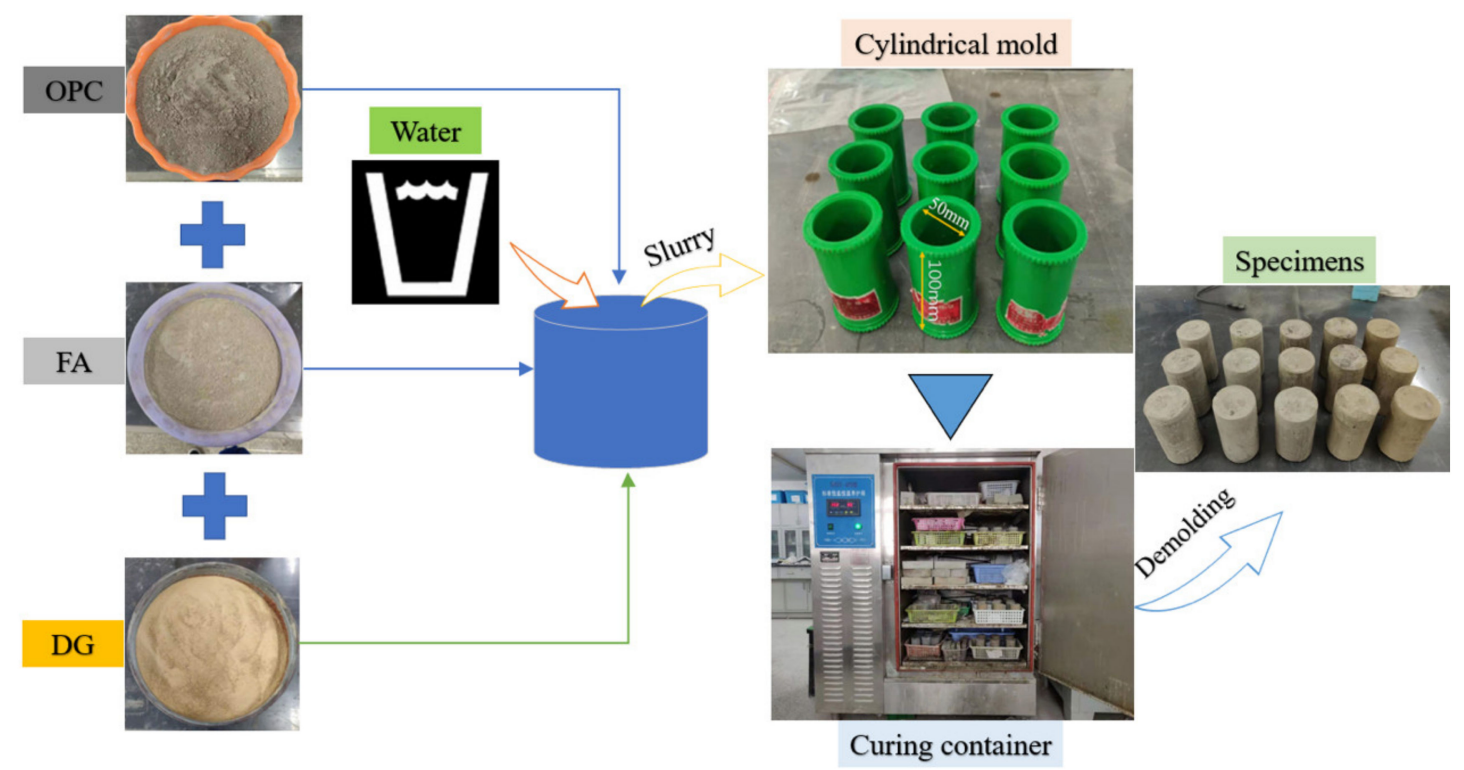

Figure 3. The preparation process of tested specimens.

In this section, the cement-to-solid waste (FA and DG) ratio was set as 1:8. Table 3 shows the proportion of each component of each sample in each group. Among them, "F-8D-0", "F-6-D-2", "F-4-D-4", "F-2-D-6", and "F-0-D-8" indicated the number of each tested specimens, the number after $\mathrm{F}$ indicated the proportion of FA for each tested specimen, and the number after D indicated the proportion of DG for each tested specimen. In the five groups, each group of six specimens, a total of 30 specimens were tested.

Table 3. The proportions of each component of each specimen.

\begin{tabular}{ccccc}
\hline No. & OPC (wt. \%) & FA (wt. \%) & DG (wt. \%) & Water (wt. \%) \\
\hline F-8-D-0 & 7.8 & 62.2 & 0.00 & 30 \\
F-6-D-2 & 7.8 & 46.7 & 15.5 & 30 \\
F-4-D-4 & 7.8 & 31.1 & 31.1 & 30 \\
F-2-D-6 & 7.8 & 15.5 & 46.7 & 30 \\
F-0-D-8 & 7.8 & 0.00 & 62.2 & 30 \\
\hline
\end{tabular}

\subsection{Uniaxial Compressive Tests}

In this study, the both ends of the tested mine fill specimens' sections were polished to ensure flatness. As shown in Figure 4, the uniaxial compressive tests were performed to obtain their uniaxial compressive strength (UCS). The wdwi-100 loading system of the Materials Center of the University of Science and Technology Beijing (Beijing) was used for UCS testing. The loading rate was set as a fixed speed of $1 \mathrm{~mm} / \mathrm{min}$. To reduce the test errors, each group of uniaxial compression tests contained three specimens to obtain the mean UCS values for the final evaluation. The experimental data could be recorded and stored in the computer during the whole loading process. 


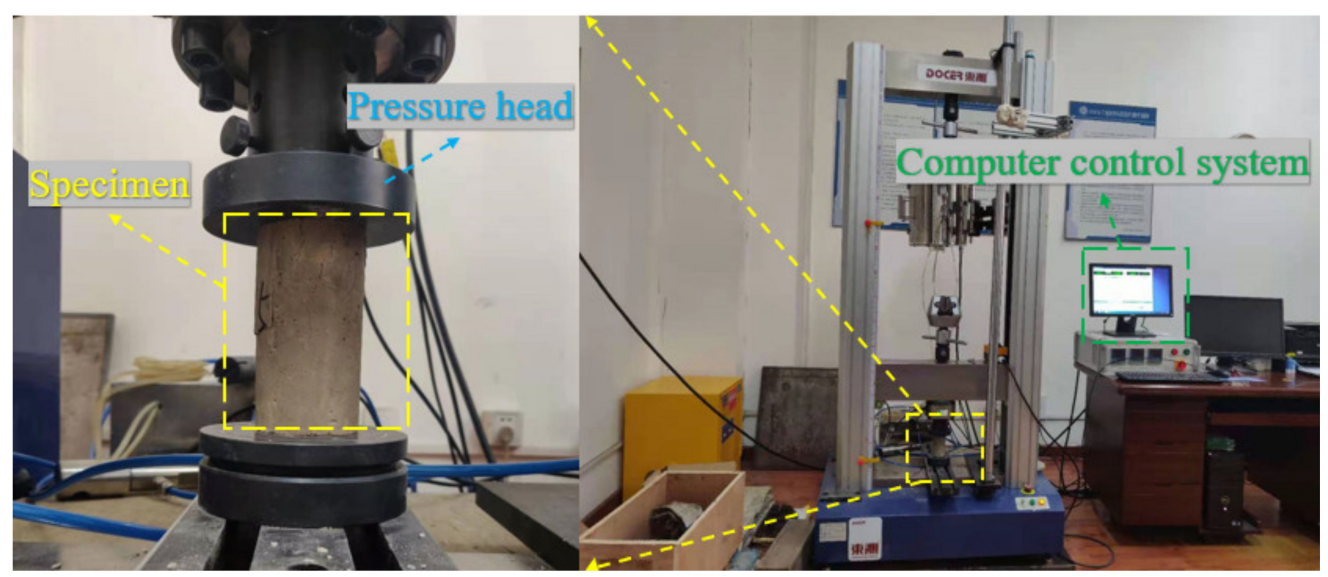

Figure 4. Photo of testing apparatus implemented in this study.

\subsection{Principle of Energy Dissipation}

It is known that the materials including rock, steel, and other cement-based materials deformed during the whole loading process [38] assuming that there was no heat exchanged between the physical process and the outside world. It was a closed system, and the total input energy generated by the external force was $U$. According to the first law of thermodynamics $[39,40]$, we could obtain the below equations.

$$
\begin{gathered}
U=\int_{0}^{\varepsilon} \sigma d \varepsilon \\
U_{e}=\frac{1}{2 E_{0}} \sigma^{2}
\end{gathered}
$$

The $U_{\mathrm{d}}$ was determined as:

$$
U_{\mathrm{d}}=U-U_{\mathrm{e}}
$$

In Equations (1)-(3), $U$ was the total input energy, $\mathrm{MJ} \cdot \mathrm{m}^{-3} ; U_{\mathrm{d}}$ was the dissipation energy, $\mathrm{MJ} \cdot \mathrm{m}^{-3} ; U_{e}$ was the strain energy that the specimens can release, $\mathrm{MJ} \cdot \mathrm{m}^{-3} ; E$ was the unloaded elastic modulus of the samples, MPa, here was replaced by the initial elastic modulus $E_{0} ; \varepsilon$ was the strain of the samples; and $\sigma$ was the sample's stress. Figure 5 showed the relationship between the dissipation energy and the releasable strain energy.

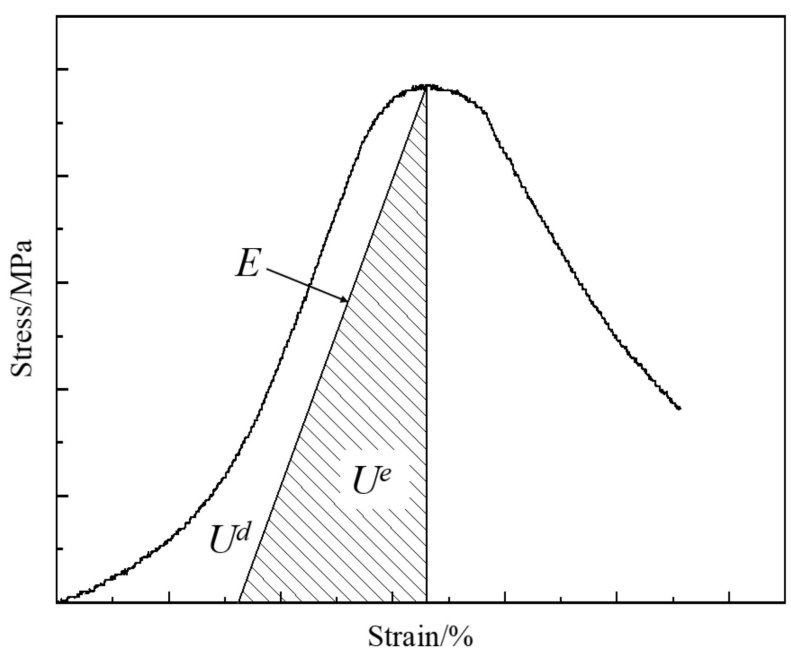

Figure 5. The relationship between $U_{\mathrm{d}}$ and $U_{e}$. 


\subsection{Scanning Electron Microscopy Analysis}

The microstructure characteristics of the mine backfill specimens were investigated using a scanning electron microscope (SEM: Zeiss EVO18, Carl Zeiss AG, Oberkochen, Germany) system. The basic parameters of the microscope used were as follows: the accelerating voltage was between 10 and $20 \mathrm{kV}$; the maximum magnification and resolution were 2000 times and $3 \mathrm{~nm}$, respectively.Before the experiment, the observed samples were dried, and then mine filling samples were sprayed with diamond by vacuum coating [41,42]. The processed samples could be observed by SEM. Figure 6 shows the SEM observation process.
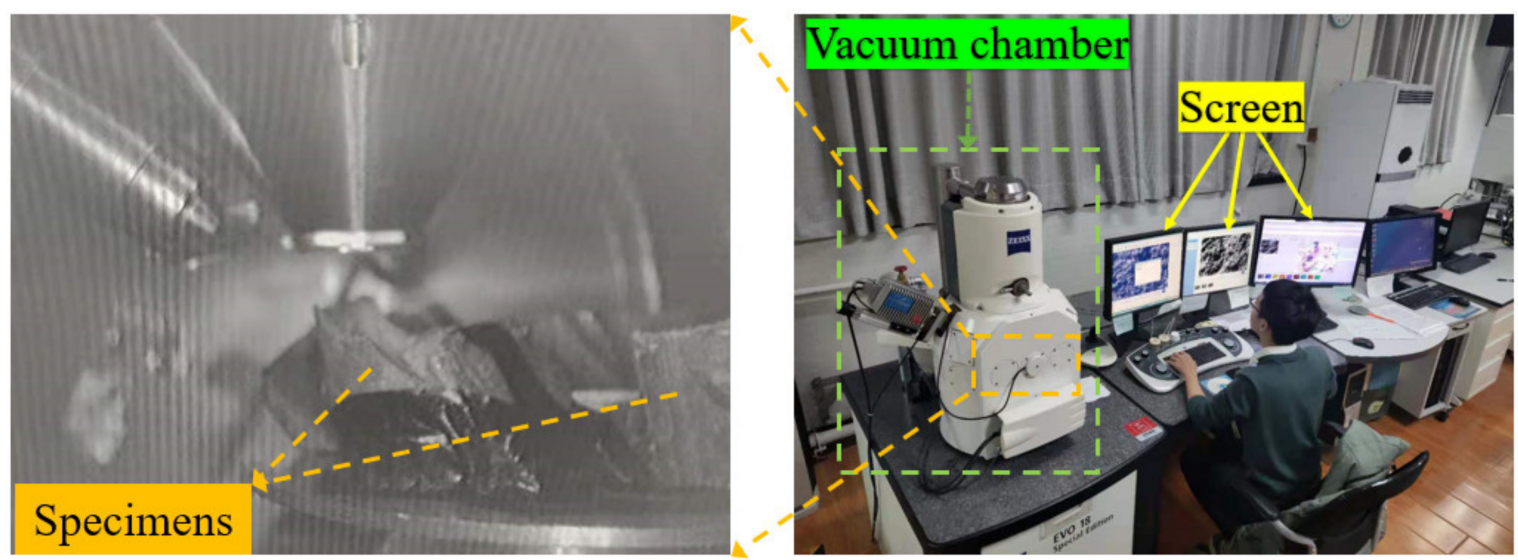

Figure 6. Photos of the used ZEISS EVO18 SEM system for microstructural investigations.

\section{Results and Discussion}

\subsection{Effect of FA/DG Ratio on the UCS}

Table 4 shows the UCS values of specimens prepared with different FA and DG proportions after curing times of 7 and 14 days. In Table 4, " 1,2 , and 3 " represented three specimens' number with the same ratio. It should be emphasized that the "F-6-D-2-2" specimens in the 7 and 14 day curing time did not meet the test requirements; therefore, the data were deleted. The average UCS values of mine fill samples prepared with different solid-to-waste ratios after curing time of 7 and 14 days were shown in Figure 7.

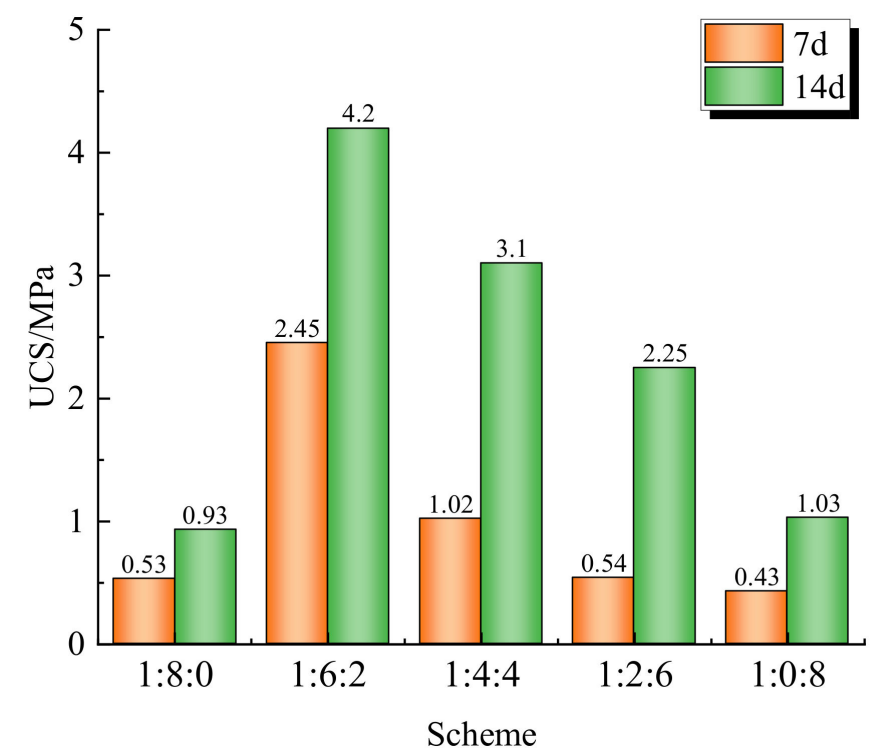

Figure 7. Average compressive strength of 7 day and 14 day cured backfill specimens. 
Table 4. The uniaxial compressive strength (UCS) results of the tested mine backfill specimens.

\begin{tabular}{cccccc}
\hline $\begin{array}{c}\text { Test } \\
\text { No. }\end{array}$ & $\begin{array}{c}\text { UCS } \\
\mathbf{( M P a}\end{array}$ & $\begin{array}{c}\text { Test } \\
\text { No. }\end{array}$ & $\begin{array}{c}\text { UCS } \\
\mathbf{( M P a )}\end{array}$ & $\begin{array}{c}\text { Test } \\
\text { No. }\end{array}$ & $\begin{array}{c}\text { UCS } \\
\mathbf{( M P a )}\end{array}$ \\
\hline F-8-D-0-1 & 0.50 & F-6-D-2-1 & 2.52 & F-4-D-4-1 & 1.03 \\
F-8-D-0-2 & 0.55 & F-6-D-2-2 & $/$ & F-4-D-4-2 & 1.00 \\
F-8-D-0-3 & 0.54 & F-6-D-2-3 & 2.45 & F-4-D-4-3 & 1.02 \\
Average: & 0.53 & Average: & 2.49 & Average: & 1.02 \\
F-2-D-6-1 & 0.53 & F-0-D-8-1 & 0.47 & & \\
F-2-D-6-2 & 0.60 & F-0-D-8-2 & 0.38 & \\
F-2-D-6-3 & 0.50 & F-0-D-8-3 & 0.44 & & \\
Average: & 0.54 & Average: & 0.43 & & \\
\hline & & Curing Times: 14 days & & \\
\hline F-8-D-0-1 & 0.96 & F-6-D-2-1 & 4.35 & F-4-D-4-1 & 3.04 \\
F-8-D-0-2 & 0.83 & F-6-D-2-2 & $/$ & F-4-D-4-2 & \\
F-8-D-0-3 & 1.00 & F-6-D-2-3 & 4.06 & F-4-D-4-3 & \\
Average: & 0.93 & Average: & 4.20 & Average: & \\
F-2-D-6-1 & 2.23 & F-0-D-8-1 & 1.07 & & \\
F-2-D-6-2 & 2.18 & F-0-D-8-2 & 1.11 & & \\
F-2-D-6-3 & 2.34 & F-0-D-8-3 & 0.91 & & \\
Average: & 2.25 & Average: & 1.03 & & \\
\hline
\end{tabular}

It could be obtained that the average UCS values of the samples cured at 7 and 14 days varies with the solid-to-waste ratios. The ideal ratio was 1:6:2 (OPC:FA:DG), the average UCS values for 7 days of curing time has reached $2.49 \mathrm{MPa}$, and the average UCS value reached $4.20 \mathrm{MPa}$ after curing time of 14 days. In addition, the average UCS values of the mine backfill specimens gradually decreased when the proportion of DG increased. However, the minimum average UCS value of the F-0-D-8 specimen was $0.43 \mathrm{MPa}$ when the curing time was 7 days. The main reason behind this behavior was that much more DG content would affect more hydration products generated inside the tested specimens. Moreover, the UCS values of tested F-8-D-0 mine fill specimens were not so large because of the hydration reaction inside the specimens was not obvious. Accordingly, the average UCS values of tested F-6-D-2 specimens in this section could meet the UCS requirement of the cut and fill mining method.

\subsection{Effect of FA/DG Ratio on Stress-Strain Relation}

Figure $8 \mathrm{a}, \mathrm{b}$ show the relationship between stress-strain of tested mine filling specimens when the curing time were 7 and 14 days, respectively.
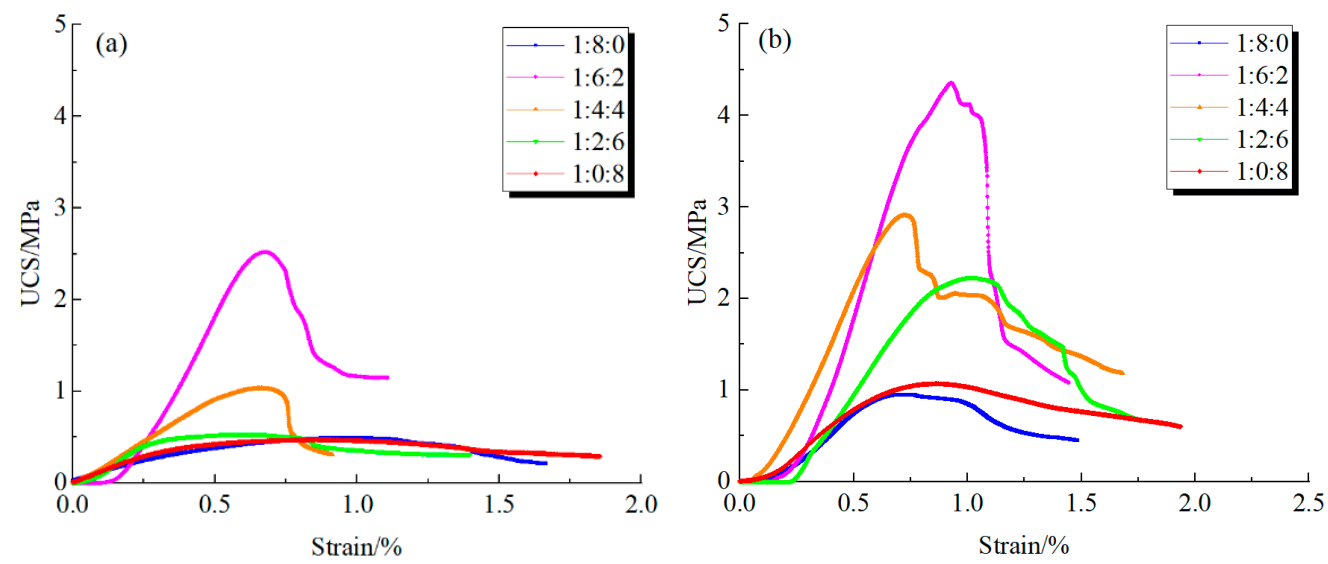

Figure 8. Stress-strain curves of the tested backfill specimens: a curing time of 7 days (a) and 14 days (b). 
In general, the stress-strain curves can divide into four stages: (1) Pore compaction stage: there would be lots of pores in the tested specimens due to FA and DG particles. These pores would be compacted when the pressure increased during this stage, resulting in a concave stress-strain curve. (2) Linear elastic stage: the strain also increased with the pressure increased. Thus, the curve became a straight line. (3) Unstable rupture stage: the elastic deformation turned into plastic deformation during this stage. The UCS values gradually reached their peak with cracks growth. (4) Crack propagation stage: after the samples reached their peak, as the pressure increased, the samples' crack expanded until samples was failed. It was also found that the F-6-D-2 and F-4-D-4 tested specimens showed strong brittleness after UCS reached the peak values. However, the UCS values of F-8-D-0, F-2-D-6, and F-0-D-8 tested mine backfill specimens were not so large. The specimens showed a good ductility after reaching their UCS values.

The UCS values of the tested specimens increased with the curing time increased. The chemical hydration reaction became more adequate, and the hydration products were more produced with time. Moreover, the hydration products filled up the pores and cracks in the tested cement-based composites specimens, resulting in denser specimens. Therefore, the UCS values of tested filling specimens were improved accordingly.

\subsection{Energy Dissipation Analysis}

Figure 9 showed the stress-strain and energy evolution curves of the tested specimens. It was found that the input energy and the dissipation energy showed a nonlinear growth trend with the axial strain increased.

However, the elastic strain energy increased firstly and then decreased combining with the specimens' failure process during the uniaxial compression tests. It was also obtained that the energy dissipation characteristics and energy distribution laws of the specimens were different in different deformation stages. The elastic strain energy in the samples occupied a dominant position before the peak failure.

Most of the input energy was converted into elastic strain energy and stored inside samples. Samples' elastic energy slows down, while the dissipated energy increased after entering the plastic rupture stage. When the crack increased sharply, the crack accelerated and expanded. After reaching the UCS location, the cracks' growth trend further increased. The elastic energy accumulated was suddenly released and converted into the dissipation energy. At last, the tested mine backfill specimens were failed eventually.
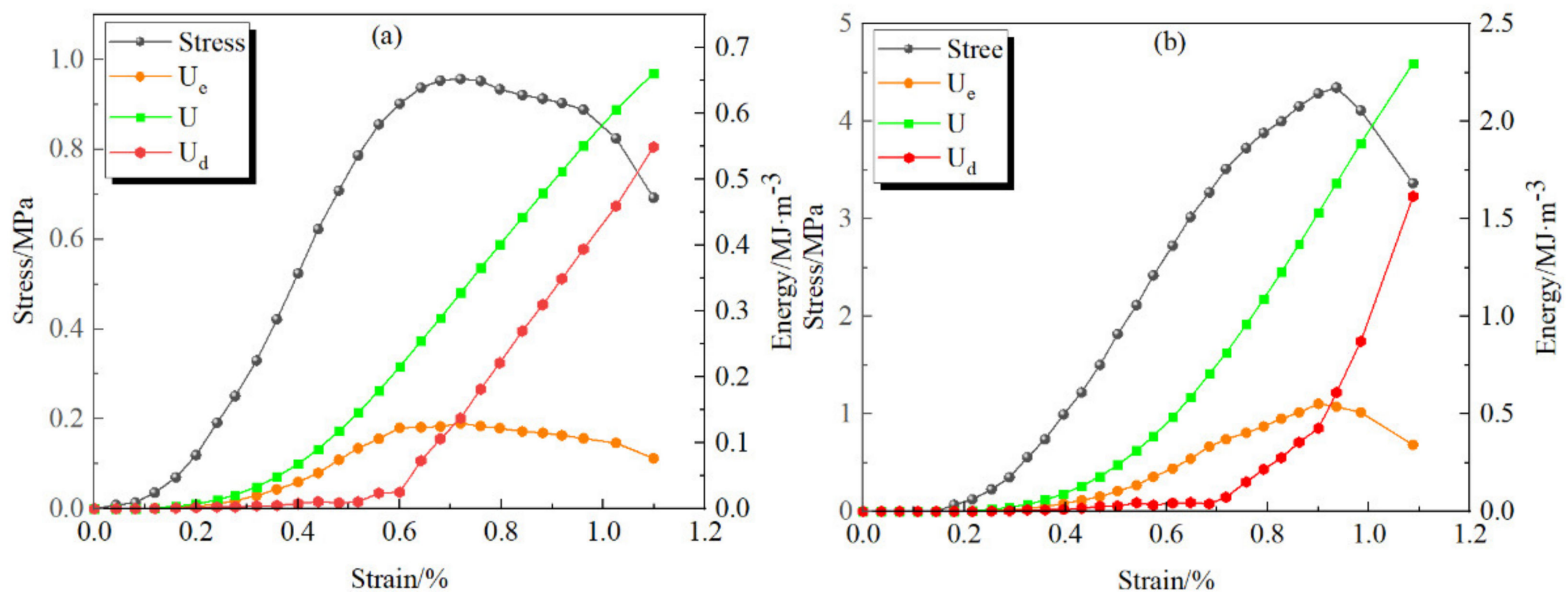

Figure 9. Cont. 


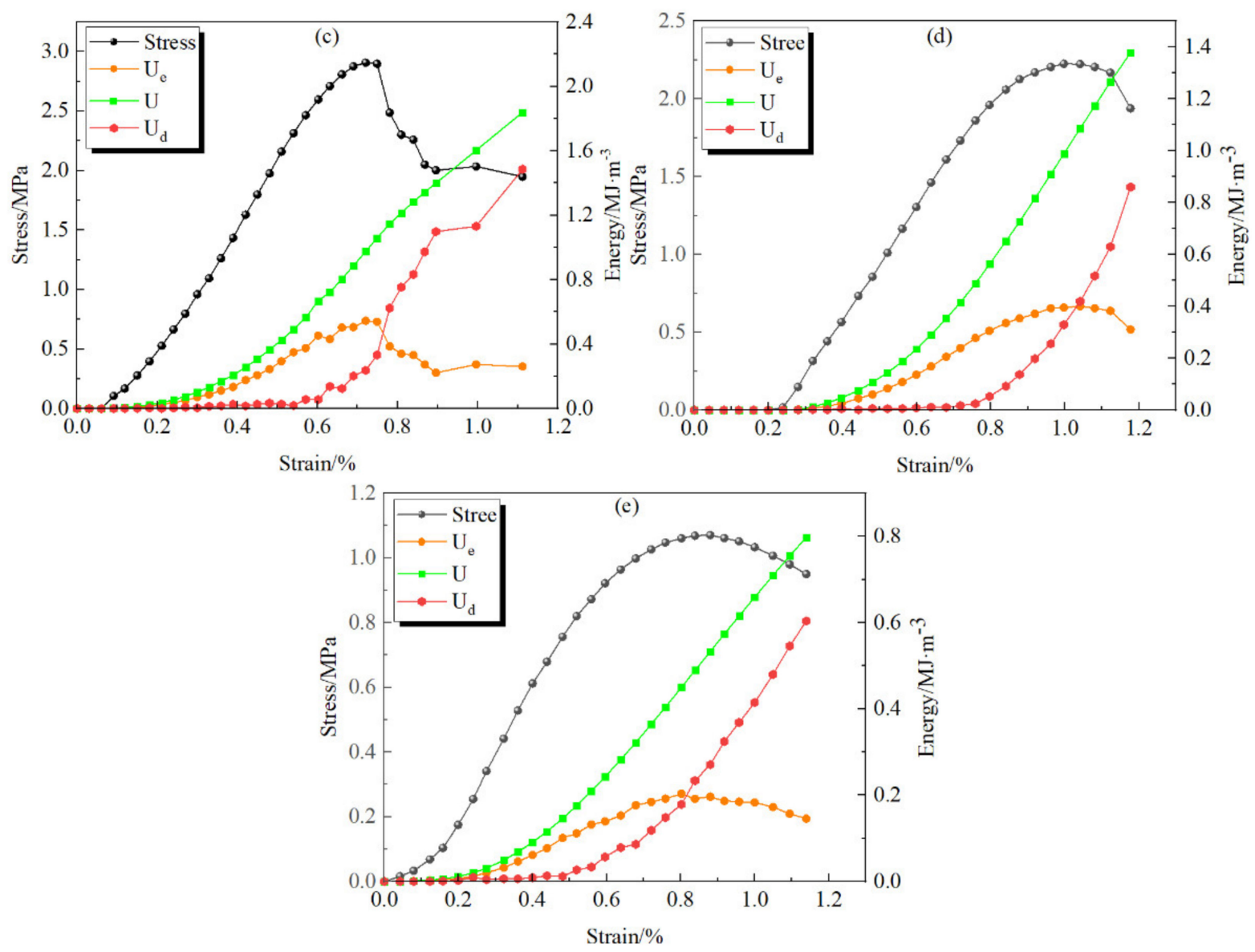

Figure 9. Samples' stress-strain and energy evolution curves: (a) F-8-D-0; (b) F-6-D-2; (c) F-4-D-4; (d) F-2-D-6; and (e) F-0-D-8.

\subsection{The Failure Modes of BMs}

Figure 10 shows the failure modes of the tested mine backfill samples with different proportions in the UCS test. It was found that the main failure modes of the F-8-D-0 and F-4-D-4 specimens were tensile failure along the loading direction. However, shear cracks mainly appeared on the surface of the F-2-D-6 and F-0-D-8 specimens. Moreover, both the shear and tensile cracks appeared on the surface of the F-6-D-2 specimen. It was also obtained that each tested mine fill sample in this study showed obvious brittleness corresponding to the stress-strain curves. With the increase of the axial loading pressure, the cement-based composites specimens showed that the accelerated crack propagation and fragments fell off the surface of the specimen. 


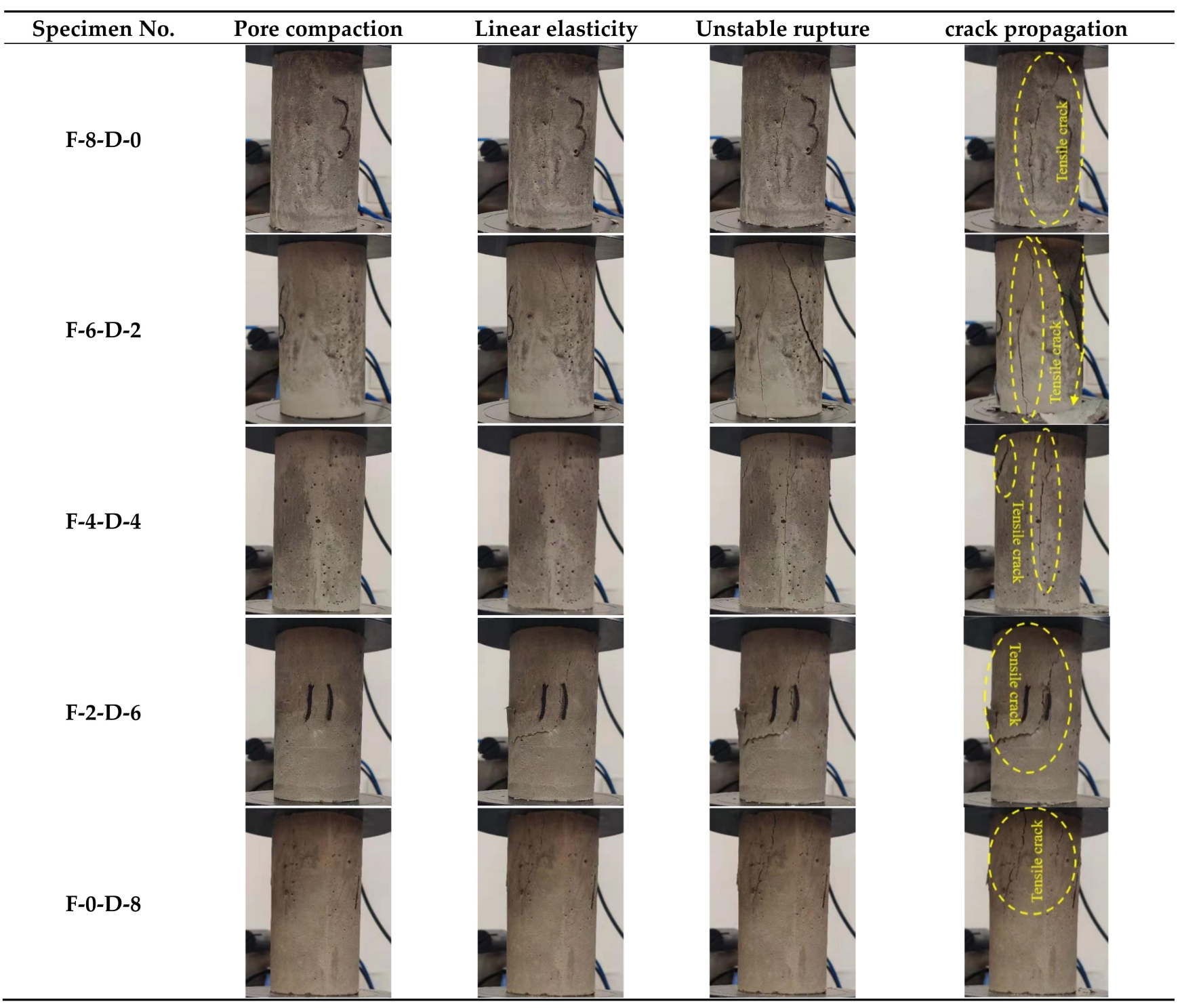

Figure 10. Failure modes of mine backfill specimens with different proportions under uniaxial compression.

\subsection{Microstructural Characteristics Analysis}

Figure 11 shows that SEM images of tested mine backfill samples with five different solid waste ratios when the curing time was 7 days. The ImageJ software was used to explore the microstructure of the tested backfill samples. Figure 11a shows the microstructural diagram of the F-8-D-0 samples. It was found that there were many large-size particles of FA on the sample's surface. There were also many pores on the tested specimen's surface. Moreover, the maximum particle size of FA and the largest pore size were $29.06 \mu \mathrm{m}$ and $24.62 \mu \mathrm{m}$, respectively. It was also found from Figure $11 \mathrm{~b}$ that a large amount of hydration products including calcium silicate hydrate (C-S-H), and few pores appeared on the solid-phase particles' surface. Moreover, the surface of the F-6-D-2 sample was much denser than other mine fill samples in this study. As shown in Figure 11c, lots of large-size pores existed on the F-4-D-4 sample's surface, and the maximum size reached $40.94 \mu \mathrm{m}$. Moreover, there were still lots of large-particle DG pieces and pores on the surface of the F-2-D-6 and F-0-D-8 mine fill samples, as demonstrated in Figure 11d,e. 

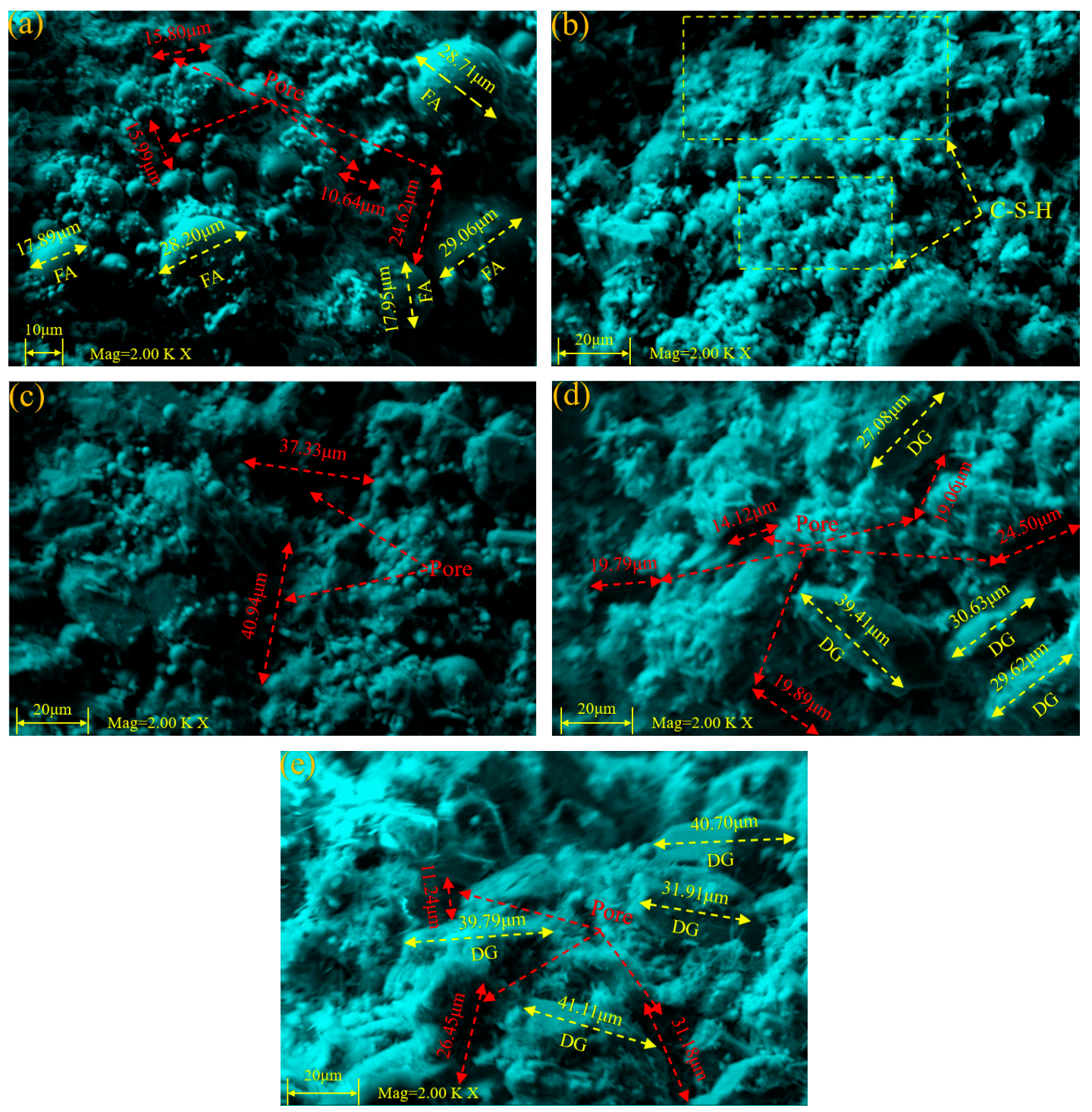

Figure 11. SEM image of 7 day cured specimens: (a) F-8-D-0; (b) F-6-D-2; (c) F-4-D-4; (d) F-2-D-6; and (e) F-0-D-8.

The element distribution mappings of the specimens' SEM images were shown from Figures 12-16. As shown in Figure 12, it was found that the $\mathrm{Si}, \mathrm{Al}$, and $\mathrm{O}$ elements were concentrated in the large amounts at the FA particles' location, which were consistent with the XRF analysis results (Figure 2). In Figure 13, the hydration reaction proceeded sufficiently and produced a large amount of flocculating substances. According to the element distribution, it was speculated that these flocculating substances were C-S-H formed by the reaction of $\mathrm{CaO}, \mathrm{Al}_{2} \mathrm{O}_{3}, \mathrm{SiO}_{2}$, and water. Moreover, the UCS values of the mine backfill specimens were strengthened because of the appearance of these $\mathrm{C}$ $\mathrm{S}-\mathrm{H}$ gels. Moreover, the elements including $\mathrm{Ca}, \mathrm{S}$, and $\mathrm{O}$ gathered in large amounts at the DG particles' locations with the proportion of DG increased, which were shown in Figures 14-16. The presence of these DG particles directly caused the UCS values of the mine backfill specimens to decrease. 

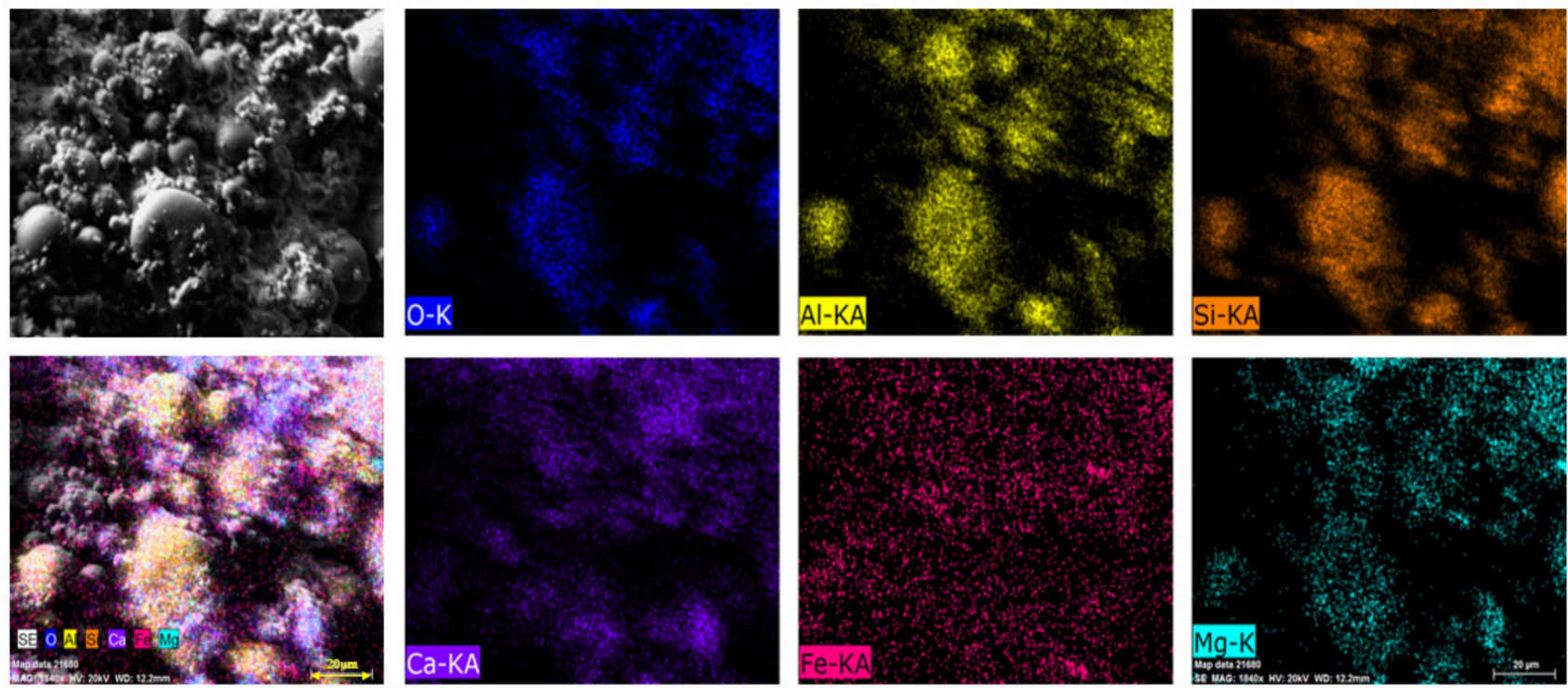

Figure 12. SEM elemental mapping of the F-8-D-0 specimen.
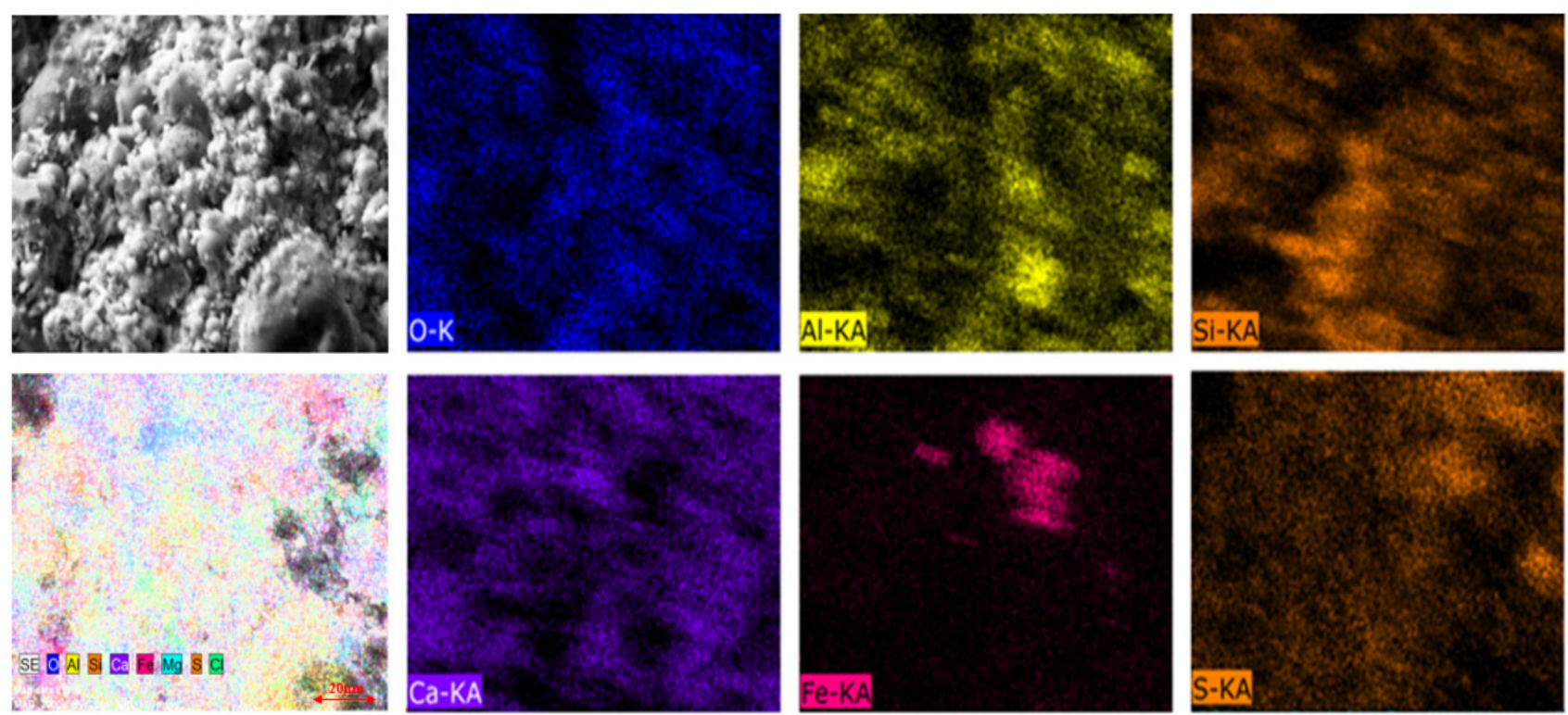

Figure 13. SEM elemental mapping of the F-6-D-2 specimen. 

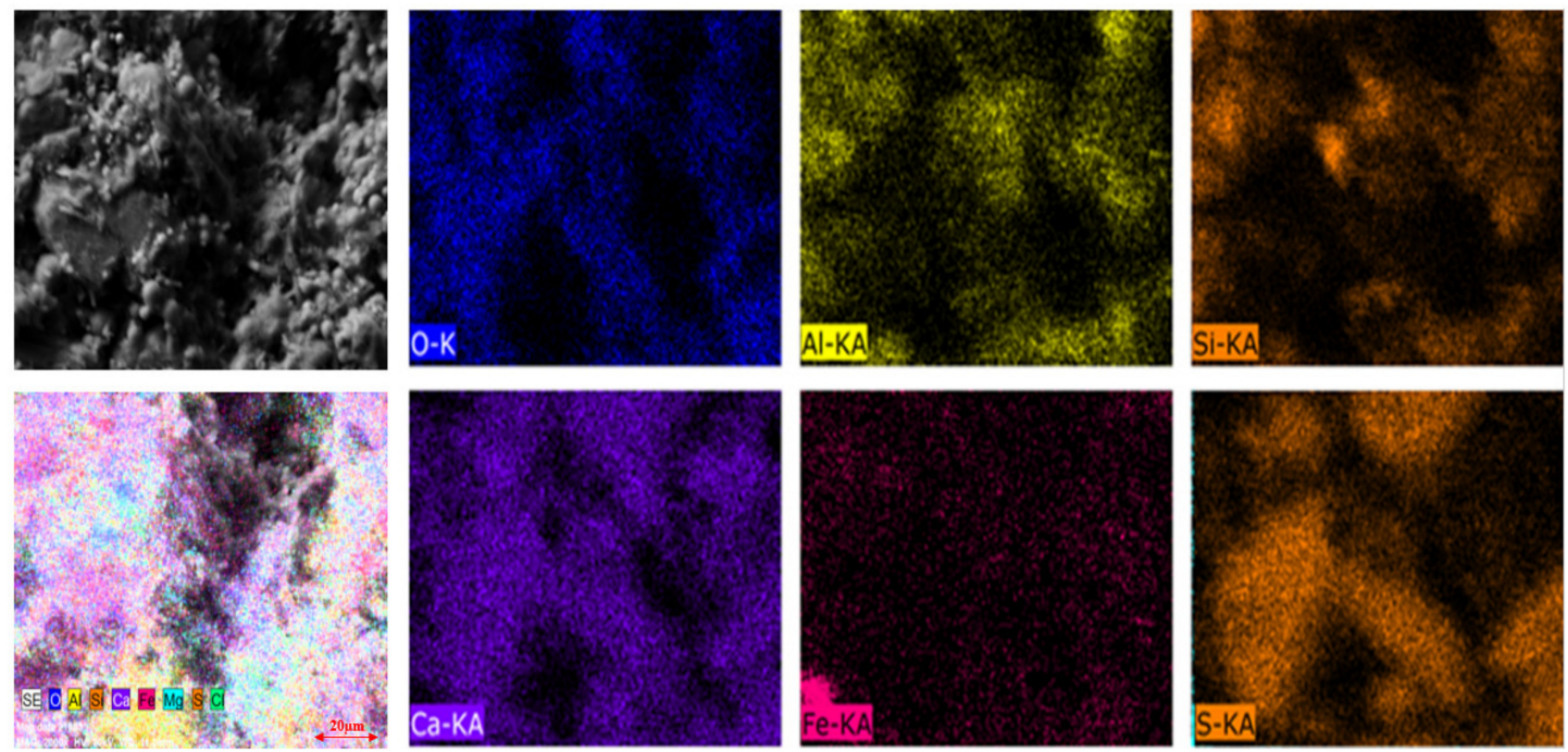

Figure 14. SEM elemental mapping of the F-4-D-4 specimen.
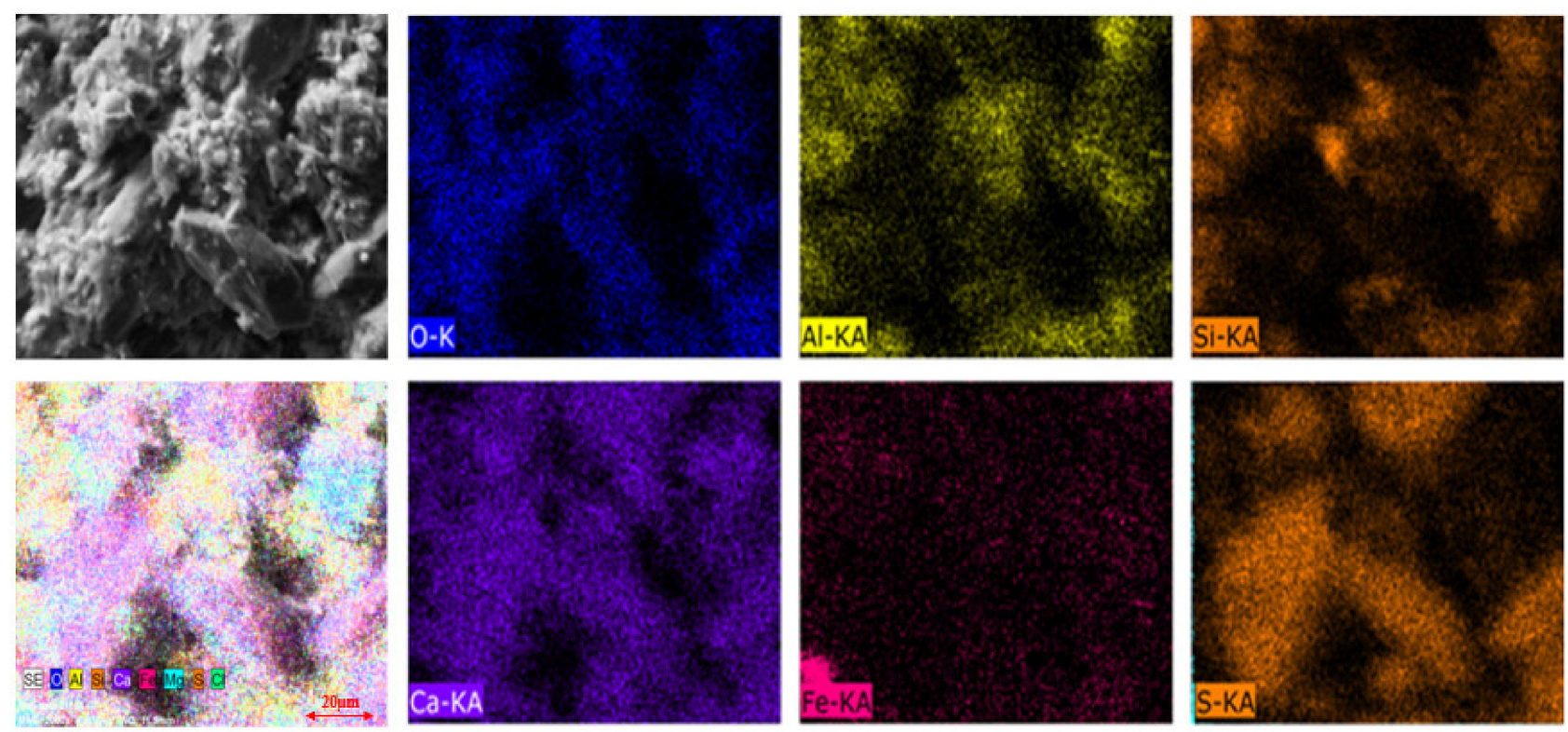

Figure 15. SEM elemental mapping of the F-2-D-6 specimen. 

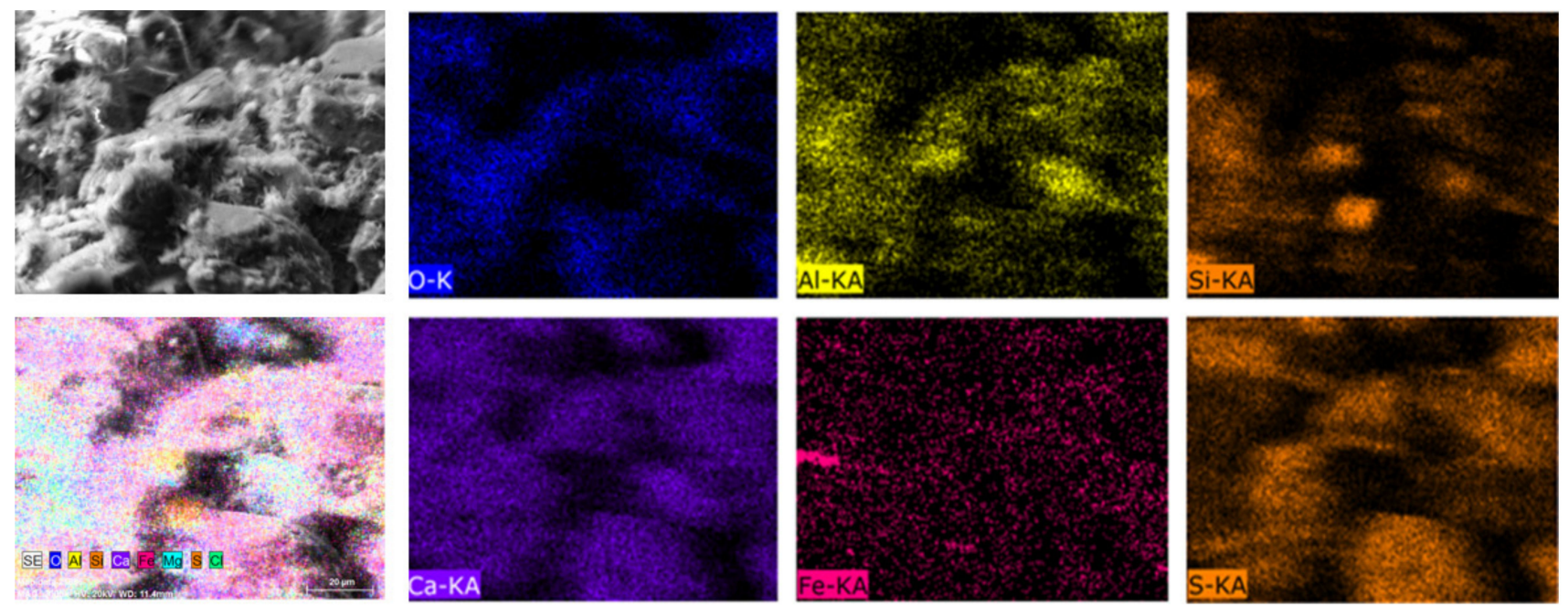

Figure 16. SEM elemental mapping of the F-0-D-8 specimen.

\section{Conclusions}

To explore the mechanical and microstructural characteristics of cement-based solid waste composites, some lab experiments such as uniaxial compressive strength, energy dissipation, and scanning electron microscopy were conducted. From the performed tests, the following results can be drawn:

(1) The UCS results shown that the ideal backfill mix (OPC:FA:DG/1:6:2) provided a strength gain of 2.49 and $4.20 \mathrm{MPa}$ for a curing time of 7 and 14 days, respectively.

(2) The mean strengths of mine fills steadily decreased with increasing DG content. The obtained strengths meet the criteria required for the cut and fill mining system.

(3) The total input energy and elastic strain energy showed a nonlinear growth trend with increasing loads. The elastic strain energy increased first and then decreased.

(4) The dissipative energy grew gradually before samples failed. The elastic energy values accumulated in samples were suddenly released and converted into dissipative energy when samples were closed to failure.

(5) A typical backfill failure mode was tensile along the loading direction and shear cracks. Samples showed obvious brittleness corresponding to their stress-strain curves.

(6) Hydration products including calcium silicate hydrate on the surface of the ideal backfill mix were denser and had less porosity, which verified the high UCS value.

As a result, the findings of this research work have proven the feasibility of using fly ash and desulfurized gypsum to prepare backfills for underground mines. It is also good to notice that further investigations on optimization of the dosages of solid wastes used within mine backfill samples are now in progress.

Author Contributions: Conceptualization, S.C.; methodology, Z.H.; writing-original draft preparation, Z.H.; writing - review and editing and supervision, E.Y. and S.C.; funding acquisition, S.C. All authors have read and agreed to the published version of the manuscript.

Funding: This research was funded by the National Natural Science Foundation of China (Grant numbers 51804017) and the Fundamental Research Funds for Central Universities (Grant number FRF-TP-20-001A2).

Data Availability Statement: No applicable.

Conflicts of Interest: The authors declare no conflict of interest. 


\section{References}

1. Zhang, W.; Zhang, Y.; Gong, J.; Yang, B.; Zhang, Z.; Wang, B.; Zhu, C.; Shi, J.; Yue, K. Comparison of the suitability of plant species for greenbelt construction based on particulate matter capture capacity, air pollution tolerance index, and antioxidant system. Environ. Pollut. 2020, 263, 114615. [CrossRef]

2. Pattanaik, A.; Mukherjee, M.; Mishra, S.; Mukharjee, M. Influence of curing condition on thermo-mechanical properties of fly ash reinforced epoxy composite. Compos. Part B Eng. 2019, 176. [CrossRef]

3. Xue, G.; Yilmaz, E.; Song, W.; Cao, S. Analysis of internal structure behavior of fiber reinforced cement-tailings matrix composites through X-ray computed tomography. Compos. Part B Eng. 2019, 175, 107091. [CrossRef]

4. Wang, D.-L.; Zhang, Q.-L.; Chen, Q.-S.; Qi, C.-C.; Feng, Y.; Xiao, C.-C. Temperature variation characteristics in flocculation settlement of tailings and its mechanism. Int. J. Miner. Met. Mater. 2020, 27, 1438-1448. [CrossRef]

5. Zhao, Y.; Taheri, A.; Karakus, M.; Chen, Z.; Deng, A. Effects of water content, water type and temperature on the rheological behaviour of slag-cement and fly ash-cement paste backfill. Int. J. Min. Sci. Technol. 2020, 30, 271-278. [CrossRef]

6. Cao, S.; Yilmaz, E.; Yin, Z.; Xue, G.; Song, W.; Sun, L. CT scanning of internal crack mechanism and strength behavior of cement-fiber-tailings matrix composites. Cem. Concr. Compos. 2021, 116, 103865. [CrossRef]

7. Wang, X.L.; Li, Q.Y.; Chen, S.C.; Yue, G.B. Application research and prospect of industrial waste in new building materials. Bull. Chin. Ceram. Soc. 2019, 38, 3456-3464.

8. Yilmaz, E.; Belem, T.; Benzaazoua, M.; Kesimal, A.; Ercikdi, B.; Cihangir, F. Use of high-density paste backfill for safe disposal of copper/zinc mine tailings. Miner. Resour. Manag. 2011, 27, 81-94.

9. Glosser, D.; Suraneni, P.; Isgor, O.B.; Weiss, W.J. Using glass content to determine the reactivity of fly ash for thermodynamic calculations. Cem. Concr. Compos. 2021, 115, 103849. [CrossRef]

10. Hansen, S.; Sadeghian, P. Recycled gypsum powder from waste drywalls combined with fly ash for partial cement replacement in concrete. J. Clean. Prod. 2020, 274, 122785. [CrossRef]

11. Jia, R.; Wang, Q.; Feng, P. A comprehensive overview of fibre-reinforced gypsum-based composites (FRGCs) in the construction field. Compos. Part B Eng. 2021, 205, 108540. [CrossRef]

12. Thymotie, A.; Chang, T.-P.; Nguyen, H.-A. Improving properties of high-volume fly ash cement paste blended with $\beta$-hemihydrate from flue gas desulfurization gypsum. Constr. Build. Mater. 2020, 261, 120494. [CrossRef]

13. Li, Y.; Liu, X.; Li, Z.; Ren, Y.; Wang, Y.; Zhang, W. Preparation, characterization and application of red mud, fly ash and desulfurized gypsum based eco-friendly road base materials. J. Clean. Prod. 2021, 284, 124777. [CrossRef]

14. Yan, B.; Lai, X.; Jia, H.; Yilmaz, E.; Hou, C. A Solution to the Time-Dependent Stress Distribution in Suborbicular Backfilled Stope Interaction with Creeping Rock. Adv. Civ. Eng. 2021, 2021, 5533980. [CrossRef]

15. Fořt, J.; Šál, J.; Ševčík, R.; Doleželováa, M.; Keppert, M.; Jerman, M.; Záleská, M.; Stehel, V.; Černýa, R. Biomass fly ash as an alternative to coal fly ash in blended cements: Functional aspects. Constr. Build. Mater. 2020, 271, 121544. [CrossRef]

16. $\mathrm{Gu}, \mathrm{K}$; Chen, B. Research on the incorporation of untreated flue gas desulfurization gypsum into magnesium oxysulfate cement. J. Clean. Prod. 2020, 271, 122497. [CrossRef]

17. Fu, B.; Liu, G.; Mian, M.; Sun, M.; Wu, D. Characteristics and speciation of heavy metals in fly ash and FGD gypsum from Chinese coal-fired power plants. Fuel 2019, 251, 593-602. [CrossRef]

18. Cavusoglu, I.; Yilmaz, E.; Yilmaz, A.O. Sodium silicate effect on setting properties, strength behavior and microstructure of cemented coal fly ash backfill. Powder Technol. 2021, 384, 17-28. [CrossRef]

19. Wang, T.; Wu, K.; Wu, M. Development of green binder systems based on flue gas desulfurization gypsum and fly ash incorporating slag or steel slag powders. Constr. Build. Mater. 2020, 265, 120275. [CrossRef]

20. Yang, L.; Jing, M.; Lu, L.; Zhu, X.; Zhao, P.; Chen, M.; Li, L.; Liu, J. Effects of modified materials prepared from wastes on the performance of flue gas desulfurization gypsum-based composite wall materials. Constr. Build. Mater. 2020, $257,119519$. [CrossRef]

21. Neto, H.F.D.S.; Pereira, W.V.D.S.; Dias, Y.N.; de Souza, E.S.; Teixeira, R.A.; de Lima, M.W.; Ramos, S.J.; Amarante, C.B.D.; Fernandes, A.R. Environmental and human health risks of arsenic in gold mining areas in the eastern Amazon. Environ. Pollut. 2020, 265, 114969. [CrossRef]

22. Li, J.; Yilmaz, E.; Cao, S. Influence of Solid Content, Cement/Tailings Ratio, and Curing Time on Rheology and Strength of Cemented Tailings Backfill. Minerals 2020, 10, 922. [CrossRef]

23. Gao, S.; Cui, X.; Kang, S.; Ding, Y. Sustainable applications for utilizing molybdenum tailings in concrete. J. Clean. Prod. 2020, 266, 122020. [CrossRef]

24. Cao, S.; Xue, G.; Song, W.; Teng, Q. Strain rate effect on dynamic mechanical properties and microstructure of cemented tailings composites. Constr. Build. Mater. 2020, 247, 118537. [CrossRef]

25. Cao, S.; Xue, G.; Yilmaz, E.; Yin, Z.; Yang, F. Utilizing concrete pillars as an environmental mining practice in underground mines. J. Clean. Prod. 2021, 278, 123433. [CrossRef]

26. Xue, G.; Yilmaz, E.; Feng, G.; Cao, S.; Sun, L. Reinforcement effect of polypropylene fiber on dynamic properties of cemented tailings backfill under SHPB impact loading. Constr. Build. Mater. 2021, 279, 122417. [CrossRef]

27. Xue, G.; Yilmaz, E.; Song, W.; Cao, S. Fiber length effect on strength properties of polypropylene fiber reinforced cemented tailings backfill specimens with different sizes. Constr. Build. Mater. 2020, 241, 118113. [CrossRef] 
28. Cao, S.; Zheng, D.; Yilmaz, E.; Yin, Z.; Xue, G.; Yang, F. Strength development and microstructure characteristics of artificial concrete pillar considering fiber type and content effects. Constr. Build. Mater. 2020, 256, 119408. [CrossRef]

29. Chen, Q.; Sun, S.; Liu, Y.; Qi, C.; Zhou, H.; Zhang, Q. Experimental and numerical study on immobilization and leaching characteristics of fluoride from phosphogypsum based cemented paste backfill. Int. J. Miner. Metall. Mater. 2021, in press. [CrossRef]

30. Jiang, H.; Yi, H.; Yilmaz, E.; Liu, S.; Qiu, J. Ultrasonic evaluation of strength properties of cemented paste backfill: Effects of mineral admixture and curing temperature. Ultrasonics 2020, 100, 105983. [CrossRef]

31. Marieta, C.; Guerrero, A.; Leon, I. Municipal solid waste incineration fly ash to produce eco-friendly binders for sustainable building construction. Waste Manag. 2021, 120, 114-124. [CrossRef]

32. Cao, S.; Xue, G.; Yilmaz, E. Flexural Behavior of Fiber Reinforced Cemented Tailings Backfill under Three-Point Bending. IEEE Access 2019, 7, 139317-139328. [CrossRef]

33. Wansom, S.; Chintasongkro, P.; Srijampan, W. Water resistant blended cements containing flue-gas desulfurization gypsum, Portland cement and fly ash for structural applications. Cem. Concr. Compos. 2019, 103, 134-148. [CrossRef]

34. Navarrete, I.; Vargas, F.; Martinez, P.; Paul, A.; Lopez, M. Flue gas desulfurization (FGD) fly ash as a sustainable, safe alternative for cement-based materials. J. Clean. Prod. 2021, 283, 124646. [CrossRef]

35. Li, J.; Zhang, S.; Wang, Q.; Ni, W.; Li, K.; Fu, P.; Hu, W.; Li, Z. Feasibility of using fly ash-slag-based binder for mine backfilling and its associated leaching risks. J. Hazard. Mater. 2020, 400, 123191. [CrossRef] [PubMed]

36. Liu, C.; Wang, F.; Zhang, M. Modelling of 3D microstructure and effective diffusivity of fly ash blended cement paste. Cem. Concr. Compos. 2020, 110, 103586. [CrossRef]

37. Yilmaz, E.; Belem, T.; Benzaazoua, M. Specimen size effect on strength behavior of cemented paste backfills subjected to different placement conditions. Eng. Geol. 2015, 185, 52-62. [CrossRef]

38. Li, P.; Cai, M.F.; Wang, P.T.; Guo, Q.F.; Miao, S.J.; Ren, F.H. Mechanical properties and energy evolution of jointed rock specimens containing an opening under uniaxial loading. Int. J. Miner. Metall. Mater. 2020. [CrossRef]

39. Cao, S.; Yilmaz, E.; Song, W.; Xue, G. Assessment of Acoustic Emission and Triaxial Mechanical Properties of Rock-Cemented Tailings Matrix Composites. Adv. Mater. Sci. Eng. 2019, 2019, 6742392. [CrossRef]

40. Han, Z.Y.; Li, D.Y.; Zhu, Q.Q.; Liu, M.; Li, X.B. Uniaxial compression failure and energy dissipation of marble specimens with flaws at the end surface. Chin. J. Eng. 2020, 12,1-10.

41. Hefni, M.; Hassani, F. Experimental development of a novel mine backfill material: Foam mine fill. Minerals 2020, 10, 564. [CrossRef]

42. Cao, S.; Yilmaz, E.; Song, W. Evaluation of viscosity, strength and microstructural properties of cemented tailings backfill. Minerals 2018, 8, 352. [CrossRef] 